\title{
Personal factors and its association with depression among secondary school children
}

\author{
Mekhala Sarkar, ${ }^{1}$ Susmita Roy, ${ }^{2}$ Mahfuza Akhter ${ }^{3}$ \\ ${ }^{1}$ Associate Professor (Psychiatry), Department of Psychotherapy, National Institute of Mental Health (NIMH), Sher-E-Bangla \\ Nagar, Dhaka, Bangladesh; ${ }^{2}$ Associate Professor, Department of Psychiatry, Jalalabad Ragib Rabeya Medical College, Sylhet, \\ Bangladesh, Senior Consultant (Skin \& VD), Shaheed Suhrawardy Medical College, Sher-E-Bangla Nagar, Dhaka, Bangladesh.
}

Article info

Received

Accepted

Number of tables

Number of figures

Number of refs
: 01 Oct. 2017

28 Feb. 2018

11

0

23

\author{
Correspondence \\ Mekhala Sarkar \\ Mobile: +8801712458977 \\ E-mail: mekhala_sarkar@yahoo.com
}

\begin{abstract}
Summary
Depression is one of the most significant mental health problems among children and adolescents. The objective of the study was to find out the personal factors and its association with depression among secondary school children in two selected schools of Dhaka, Bangladesh. It was a crosssectional study conducted from November 2008 to October 2009 among one boys' and one girls' school of Dhaka, Bangladesh. Purposive sampling technique was used to select 144 respondents from class VI to class IX. A self administered semi-structured questionnaire was used to assess the personal factors of children whereas the Center for Epidemiologic Studies Depression Scale for Children (CES-DC) was used to assess their depressive status. The results showed that 13 to 15 years age group constituted the highest proportion which was followed by the age group of 10 to 12 years. There was no significant difference of age of the respondents with or without depression $(p>0.05)$. It was found that girls were two times more likely to have depression than boys. Among all the respondents, 43 students (29.9\%) were suffering from depression. Depression was found highest (36.1\%) among the respondents of class VIII but no significant association was found between the presence of depression and educational status of the respondents $(p>0.05)$. Depression was found to be proportionately higher among occasional or regular smokers in comparison to those who never smoked. The overall result of the study indicates that possibility of depression is considerably present in school-going children. So, arrangement for the school mental health services is of utmost importance.
\end{abstract}

Bang J Psychiatry 2016;30(1):1-6

\section{Introduction}

Childhood depression is a matter of major concern because of its prevalence, potential for recurrence and impairment of functioning ${ }^{1,2}$. Early depressive vulnerability is an extrapolative factor for depression in adulthood. ${ }^{3}$ When the number of areas and the speed of change to which adolescents must adapt increase in comparison to childhood, the number of teenagers with mental health problems rises accordingly. ${ }^{4}$ Hence, currently, more adolescents are reported to experience mental health problems compared to the past. ${ }^{5}$

Studies conducted on the prevalence of depression among adolescents have showed that the prevalence ranged from $5 \%$ to $20 \% .{ }^{6}$ A hospital-based study among inpatient children and adolescents in Bangladesh showed that the proportion of depression among overall psychiatric morbidity was $2.46 \%{ }^{7}$ In other studies conducted among the outpatient children and adolescents found that the proportion of emotional disorders and depressive disorders were $32.5 \%$ and $3.6 \%$ respectively. ${ }^{8,9}$ In another study of Bangladesh, emotional disorder was found $3.2 \%$ among all behavioural disorders in primary school children. ${ }^{10} \mathrm{An} \mathrm{NIMH}$-sponsored study of 9 to 17 -year-olds estimated that the prevalence of any depression was more than $6 \%$ in a 6 -month period, with $4.9 \%$ having major depressive disorder. Here, it was reported that depressive disorders occur in approximately $2 \%$ of primary school children and 4 to $8 \%$ of adolescents. ${ }^{11}$

Substance misuse is consistently reported with markedly impaired emotional functioning. ${ }^{12} \mathrm{~A}$ cross sectional descriptive study of Selangor, Malaysia found that among the students with depression, $1 \%$ were smoker, $4.1 \%$ took alcohol and $0.9 \%$ took other drugs. ${ }^{13}$ Adolescent depression is also related to some school-related characteristics like failure at school and a low grade point average. ${ }^{14,15}$

In spite of the significance of the issue, the number of related studies is inadequate in Bangladesh. Information regarding depression among the adolescents in Bangladesh is very scanty. So, considering all relevant findings, this study attempted to determine the personal factors and its 
association with depression among the secondary school children and adolescents in selected schools of Dhaka city.

\section{Materials and methods}

This was a cross sectional study conducted from November 2008 to October 2009 among 144 school children in two selected public schools in Dhaka city named Dhanmondi Government Boys High School and Dhanmondi Government Girls High School. For the convenience of the study, one boys' and one girls' school were selected. All secondary school students from class VI to IX, aged less than 18 years were the study population. Convenient sampling technique was used. Considering the effect of stress on Secondary School Certificate (SSC) examination, students of class $X$ and who were on medication for last one month or suffering from any acute or chronic illness from last one week or unable to attend the school on the selected date of data collection had been excluded from the study. A self-administered semi-structured questionnaire was developed in English; then translated to Bengali contained questions related to personal factors like age, sex, educational information (level of class, class roll number, total numbers in last examination), smoking status and satisfaction with body image. The Center for Epidemiologic Studies Depression Scale for Children (CES-DC) was used to assess the depressive status. ${ }^{6,16}$ Ethical issues were maintained properly throughout the study. After collecting data, editing was done manually and was analyzed with the help of Statistical Package for the Social Sciences (SPSS) software package version 12. Chi-square test was done between discrete variables to check for the statistically significant association between different variables. Student's t-test of significance was performed to determine whether there was an observed difference of the means of continuous variables between two groups of having depressive symptoms and not having depressive symptoms. The odds ratio (OR) with 95\% confidence interval $(\mathrm{Cl})$ for risk factors was calculated taking the least proportionate clinically relevant criteria as reference value. All the tests were two tailed and $p<0.05$ was considered to be statistically significant.

\section{Results}

The results showed that, 13 to 15 years age group constituted the highest portion of the respondents, which was followed by the age group of 10 to 12 years. The mean $( \pm S D)$ age of boys and girls was calculated as $13.07( \pm 1.47)$ years and $12.76( \pm 1.40)$ years respectively. Among total study population the mean $( \pm S D)$ age and mode were $12.92( \pm 1.46)$ and 12 years respectively (Table 1 ). The proportion of depression was found to be higher among the girls than among boys ( $40.3 \%$ versus $19.4 \%$ ). This difference was also found to be statistically significant $\left(\chi^{2}{ }_{(1)}=7.460, p<0.05\right)$. It was found that girls were two times more likely to have depression than boys $(\mathrm{OR}=2.79 ; \mathrm{Cl}=1.32-5.91)$ (Table 2). The present study estimated that among 144 students, 43 students $(29.9 \%)$ were suffering from some level of depression. The Student's t-test showed that there was no significant difference of age of the respondents with or without depression ( $p>0.05$ ) (Table 3 ). In boys' school, depression was mostly prevalent among the students of class VIII (27.8\%) and in girls' school, it was found in highest proportion among the students of class VI (50.0\%) (Table 4). According to the educational status, depression was found as highest proportion (36.1\%) among the respondents who studied in class VIII but no significant association was found between the presence of depression and educational status of the respondents $(p>0.05)$ (Table 5$)$. It was found that total number in the last examination or class roll number of the respondents according to merit had no significant influence in the presence of depression (Table 6 and Table 7). Distribution of the respondents on the basis of smoking status showed that four $(22.2 \%)$ students of class VIII and four $(22.2 \%)$ of class IX smoked regularly or occasionally and only one student from each class of VI and VII agreed the habit of smoking. No respondent from girls' school found to have this habit (Table 8). Among the respondents, depression was found to be proportionately higher who smoked occasionally or regularly in comparison to those who never smoked, though this difference was not statistically significant (Table 9). In boys' school, major proportion of the respondents (33.3\%), dissatisfied with body image was found among the students of class IX. In girls' school, except for class VIII, same proportion of the respondents $(22.2 \%)$ of class VI, VII and class IX were found to be dissatisfied with their body image (Table 10). This difference was not statistically significant (Table 11).

Table 1: Age of the respondents $(n=144)$

\begin{tabular}{lccc}
\hline Age (in years) & Boys & Girls & Total \\
& Frequency (\%) & Frequency (\%) & Frequency (\%) \\
\hline $10-12$ & $33(45.8 \%)$ & $32(44.4 \%)$ & $65(45.1 \%)$ \\
$13-15$ & $37(51.4 \%)$ & $38(52.8 \%)$ & $75(52.1 \%)$ \\
$\geq 16$ & $2(2.8 \%)$ & $2(2.8 \%)$ & $4(2.8 \%)$ \\
Mean ( $\pm S D) ;$ Mode (in years) & $13.0( \pm 1.47) ; 12$ & $12.76( \pm 1.4) ; 13$ & $12.92( \pm 1.46) ; 12$ \\
Age range (in years) & $10-16$ & $10-17$ & $10-17$ \\
\hline
\end{tabular}


Table 2: Sex and presence of depression $(n=144)$

\begin{tabular}{lcccc}
\hline Sex & \multicolumn{2}{c}{ Presence of depression } & Total (\%) & Test statistic \\
\cline { 2 - 4 } & Yes (\%) & No $(\%)$ & $72(50.0)$ & $\chi_{(1)}^{2}=7.460$ \\
Boys & $14(19.4)$ & $58(80.6)$ & & $p=0.006$ \\
Girls & & & $72(50.0)$ & OR=2.79; Cl=1.32- 5.91 \\
\hline
\end{tabular}

Table 3: Age and presence of depression $(n=144)$

\begin{tabular}{lcccc}
\hline Characteristics & Presence of depression & Number of respondents & Mean \pm SD & Test statistic \\
\hline Age of respondents & Yes & 43 & $13.09 \pm 1.360$ & $t_{(142)}=0.955 p=0.170$ \\
(in years) & No & 101 & $12.84 \pm 1.481$ & \\
\hline
\end{tabular}

Table 4: Level of education and presence of depression according to sex $(n=144)$

\begin{tabular}{llccccc}
\hline Characteristics & \multicolumn{2}{c}{ Boys } & & \multicolumn{2}{c}{ Girls } \\
\cline { 3 - 6 } & & Yes & No & & Yes & No \\
\hline Presence of depression & Class VI & $1(5.6 \%)$ & $17(94.4 \%)$ & & $9(50.0 \%)$ & $9(50.0 \%)$ \\
& Class VII & $4(22.2 \%)$ & $14(77.8 \%)$ & & $5(27.8 \%)$ & $13(72.2 \%)$ \\
& Class VIII & $5(27.8 \%)$ & $13(72.2 \%)$ & $8(44.4 \%)$ & $10(55.6 \%)$ \\
& Class IX & $4(22.2 \%)$ & $14(77.8 \%)$ & & $7(38.9 \%)$ & $11(61.1 \%)$ \\
\hline
\end{tabular}

Table 5: Educational status and presence of depression $(n=144)$

\begin{tabular}{|c|c|c|c|c|}
\hline \multirow{2}{*}{$\begin{array}{l}\text { Educational status of the } \\
\text { respondents }\end{array}$} & \multicolumn{2}{|c|}{ Presence of depression } & \multirow[t]{2}{*}{ Total (\%) } & \multirow[t]{2}{*}{ Test statistic } \\
\hline & Frequency Yes (\%) & Frequency No (\%) & & \\
\hline Class VI & $10(27.8)$ & $26(72.2)$ & $36(25.0)$ & $c^{2}{ }_{(3)}=1.16 p=0.239$ \\
\hline Class VII & $9(25.0)$ & $27(75.0)$ & $36(25.0)$ & \\
\hline Class VIII & $13(36.1)$ & $23(63.9)$ & $36(25.0)$ & \\
\hline Class IX & $11(30.6)$ & $25(69.4)$ & $36(25.0)$ & \\
\hline
\end{tabular}

Table 6: Total score obtained in last examination and presence of depression $(n=144)$

\begin{tabular}{lcccc}
\hline & $\begin{array}{c}\text { Presence of } \\
\text { depression }\end{array}$ & $\begin{array}{c}\text { Number of } \\
\text { respondents }\end{array}$ & Mean \pm SD & Test statistic \\
\hline Total number in the & Yes & 43 & $644.42 \pm 79.90$ & $\mathrm{t}_{(142)}=-1.347 \mathrm{p}=0.180$ \\
last examination & No & 101 & $664.71 \pm 83.93$ & \\
\hline
\end{tabular}

Table 7: Roll number of the respondents and presence of depression $(n=144)$

\begin{tabular}{|c|c|c|c|c|}
\hline \multirow{2}{*}{$\begin{array}{l}\text { Class roll number of the } \\
\text { respondents }\end{array}$} & \multicolumn{2}{|c|}{ Presence of depression } & \multirow[t]{2}{*}{ Total (\%) } & \multirow[t]{2}{*}{ Test statistic } \\
\hline & Yes (\%) & No $(\%)$ & & \\
\hline $1-10$ & $3(18.8)$ & $13(81.3)$ & $16(11.3)$ & $\chi_{(5)}^{2}=6.529 p=0.258$ \\
\hline $11-20$ & $8(29.6)$ & $19(70.4)$ & $27(19)$ & \\
\hline $21-30$ & $12(42.9)$ & $16(57.1)$ & $28(19.7)$ & \\
\hline $31-40$ & $4(15.4)$ & $22(84.6)$ & $26(18.3)$ & \\
\hline $41-50$ & $9(37.5$ & $15(62.5)$ & $24(16.9)$ & \\
\hline $51-60$ & $7(33.3)$ & $14(66.7)$ & $21(14.8)$ & \\
\hline
\end{tabular}


Table 8: Smoking status of the respondents $(n=144)$

\begin{tabular}{|c|c|c|c|c|c|}
\hline \multirow[t]{2}{*}{ Characteristics } & & \multicolumn{2}{|c|}{ Boys(Percentage) } & \multicolumn{2}{|c|}{ Girls (Percentage) } \\
\hline & & Yes (\%) & No $(\%)$ & Yes (\%) & No $(\%)$ \\
\hline \multirow[t]{4}{*}{ Smoking status of the respondents } & Class VI & $1(5.6 \%)$ & $17(94.4 \%)$ & $0(0 \%)$ & $18(100 \%)$ \\
\hline & Class VII & $1(5.6 \%)$ & $17(94.4 \%)$ & $0(0 \%)$ & $18(100 \%)$ \\
\hline & Class VIII & $4(22.2 \%)$ & $14(77.8 \%)$ & $0(0 \%)$ & $18(100 \%)$ \\
\hline & Class IX & $4(22.2 \%)$ & $14(77.8 \%)$ & $0(0 \%)$ & $18(100 \%)$ \\
\hline
\end{tabular}

Table 9: Smoking status and presence of depression $(n=144)$

\begin{tabular}{lcccc}
\hline Smoking status & \multicolumn{2}{c}{ Presence of depression } & Total (\%) & Test statistic \\
\cline { 2 - 3 } & Yes (\%) & No (\%) & \\
\hline Smoker & $4(40.0)$ & $6(60.0)$ & $10(13.9)$ & ${ }^{*} \mathrm{p}=0.095$ \\
Non-smoker & $10(16.1)$ & $52(83.9)$ & $62(86.1)$ & \\
\hline
\end{tabular}

*Fisher's exact test was done

Table 10: Satisfaction with body image of the respondents $(n=144)$

\begin{tabular}{lllllll}
\hline Characteristics & & \multicolumn{2}{c}{ Boys(Percentage) } & & \multicolumn{2}{c}{ Girls(Percentage) } \\
\cline { 3 - 4 } \cline { 5 - 7 } & & Yes & No & & Yes & No \\
\hline Satisfaction with body image & Class VI & 94.4 & 5.6 & & 77.8 & 22.2 \\
& Class VII & 72.2 & 27.8 & & 77.8 & 22.2 \\
& Class VIII & 77.8 & 22.2 & & 83.3 & 16.7 \\
& Class IX & 66.7 & 33.3 & & 77.8 & 22.2 \\
\hline
\end{tabular}

Table 11: Satisfaction with body image and presence of depression $(n=144)$

\begin{tabular}{llccccc}
\hline Satisfaction with body image & & \multicolumn{2}{c}{ Presence of depression } & & Total (\%) & Test statistic \\
\cline { 2 - 4 } & & Yes (\%) & No (\%) & & \\
\hline Boys & Yes & $9(16.1)$ & $47(83.9)$ & $56(77.8)$ & ${ }^{*} \mathrm{p}=0.280$ \\
& No & $5(31.3)$ & $11(68.8)$ & $16(22.2)$ & \\
Girls & Yes & $20(35.1)$ & $37(86.0)$ & $57(79.2)$ & $\chi^{2}(1)=3.064 \mathrm{p}=0.080$ \\
& No & $9(60.0)$ & $6(40.0)$ & $15(20.8)$ & & \\
\hline
\end{tabular}

*Fisher's exact test was done

\section{Discussion}

In this study, depression was diagnosed in 43 students $(29.9 \%)$ among the total of 144 . Prevalence of depression among children and adolescents varies widely in previous studies (5\% to $20 \%$ ) due to the use of different settings in terms of study place, study population with different age range and most importantly, different depression scales. ${ }^{16,17}$ In the present study, depression was measured by CES-DC which was actually a screening tool. So, this tool only predicted the possibility of having depression rather than true presence. However, the limited number of studies of depression in the world especially in the Asian region also pointed to a similar alarming picture. A well conducted study among high school students in Turkey using Children's Depression Inventory (CDI) scale found that $17.5 \%$ had depression. ${ }^{18}$ Using the same scale, another study done among secondary school children in the state of Selangor, Malaysia detected $10.3 \%$ school children with depression. ${ }^{13}$ The findings of previous studies appeared to have lower prevalence rate of depression in comparison with the present study finding. The reason can be explained by several factors. Firstly, all the study findings were obtained from developed countries whereas the present study was undertaken in Bangladesh where socioeconomic condition was much lagged behind. Besides, different cultural practices could have also contributed to the result. Secondly, most of the studies cited above used different instruments for detection of depression whereas the present study used CES-DC which was also widely used. In addition different methodology specially sampling technique, sample size, study population might have played a role. However, though the 
proportion of depression in this study was found little higher in the study, the use of stratified sampling in collecting sample unit helped to strengthen the result of the present study.

In this study, while the proportion of girls with depression was found $40.3 \%$, the proportion of boys with depression was found $19.4 \%$. This wide difference according to gender in terms of depression was also statistically significant. This result was also in agreement with previous studies done among Turkish children (male 15.3\%; females 19.4\%; $p<0.05$ ). ${ }^{18}$ This finding was also supported by Birmaher B et al in the review of childhood and adolescent depression in the past 10 years where it was said that adolescent girls were twice more likely to have depression. ${ }^{19}$ Regardless of age, females are generally more susceptible to depression, due to patterns of help-seeking behaviours and multiple life events. Before the age of 13 years, the prevalence of childhood depression was equal between genders, but increased significantly in females after they reached the age of 14 , though this was not a uniform finding. ${ }^{20}$

The age range for all of the respondents in the current study was 10 to 17 years. Majority of the respondents were within the age group of 13 to 15 years. The mean ( $\pm S D$ ) age of the respondents was $12.92( \pm 1.46)$ years. It was found that those who had higher mean age were more depressed but this mean age difference between the respondents with and without depression was not statistically significant. This finding is similar to the results of the studies conducted by Mehmet $\mathrm{E}$ et al, Reinherz HZ et al and Ramli M et al. ${ }^{18,21,22}$

In this study only the students of class VI to Class IX in two boys' and girls' schools were selected and students of class VIII were found more depressed in comparison to other classes but no significant association with depression was revealed in this regard. Information on personal matters specially on smoking habit, substance abuse and perceived body image were always subjected to some information bias. Participants sometimes gave socially desirable responses rather than true ones. To reduce these biases, attempts were made such as the data were collected anonymously. During data collection, the interviewer had given a considerable period of time for making a good rapport with the respondents, more sensitive questions were asked in the later part of the interview and assurance was given about maintenance of full confidentiality. Nonetheless, there might be at least some information bias. For adolescents, academic success was of considerable importance. The mean score of the total number in the last examination was lower among those who had depression but statistical significance was not found in this regard. Nonetheless, previous study done among high school students by Mehmet E et al found that low GPA was related to high depression score in adolescents. ${ }^{18}$

The present study showed that proportion of depression was higher among those girls who were not satisfied with their body image than those who were satisfied with their body image and this finding was statistically significant $(p=0.080)$. Previous studies found that significant differences in the risk of developing depressive symptoms were associated with the subjective sense of body image. ${ }^{23}$ Presence of smoking was found only among boys. Depression was found higher among those who smoked regularly or occasionally than the nonsmokers. The habit of smoking escaped a very narrow margin to show any significant association with depression $(p=0.09)$. Anyway, this finding was consistent with other study findings by Mehmet E et al and Ramli M et al among Turkish school as well as Malaysian school students respectively. ${ }^{18,21}$

\section{Conclusion}

Though the scale used to measure depression was not standardized and validated in the context of Bangladesh and some personal information given by the respondents were subjective, the overall result of the study indicates that possibility of depression is considerably present in school-going children. So appropriate arrangement of the school mental health services could be devised by our strategy-makers to find out depression and associated risk factors in this group.

\section{References}

1. Hamrin V, Pachler MC. Child and adolescent depression: review of the latest evidence-based treatments. J Psychosoc Nurse 2005;43:54-63.

2. Dopheide JA. Recognizing and treating depression in children and adolescents. Am J Health Syst Pharmacology 2006;63: 233-43.

3. Lewinsohn PM, Roberts RE, Seeley JR. Adolescent psychopathology: II. Psychosocial risk factors for depression. J Abnorm Psychol 1994;103:302-15.

4. Kim YH. Correlation of mental health problems with psychological constructs in adolescence: final results from a 2-year study. Int J Nurs Study 2003;40:115-24.

5. Collishaw S, Maughan B, Goodman R. Time trends in adolescent mental health. J Child Psychol Psychiatry 2004;45:1350-62.

6. Saluja G, lachan R, Scheidt PC. Prevalence of and risk factors for depressive symptoms among young adolescents. Arch Pediatr Adolesc Medicine 2004;158:760-5.

7. Alam MF, Hasan N, Ali M, Azad MC, Bashar K, Akter F, et al. Multiaxial diagnosis of child and adolescent psychiatric disorders in inpatient department of National Institute of Mental Health, Dhaka. Bang J Psychiatry 2004;18(2):55-65.

8. Mullick MSI, Khanam M, Islam H. Psychiatric morbidity of outpatient children in institute of mental health and research. Bang J Psychiatry 1995;7(1):4-8. 
9. Sarkar M, Khan MZR, FirozAHM, Rabbani MG, Alam MF. Pattern of psychiatric morbidity among children and adolescents attending child guidance clinic of National Institute of Mental Health, Dhaka. Bang J Psychiatry 2008;22(1):11-21.

10. Rabbani MG, Hossain MM. Behaviour disorder in urban primary school in Dhaka, Bangladesh. Pub Health 1999;113:233-6.

11. Kessler RC, Walters EE. Epidemiology of DSM-III-R major depression and minor depression among adolescents and young adults in the National Comorbidity Survey. Depress Anxiety 1998;7:3-14.

12. Krupnick JL, Green BL, Stockton P, Goodman L, Corcoran C, Petty R. Mental health effects of adolescent trauma exposure in a female college sample: exploring differential outcomes based on experiences of unique trauma types and dimensions. Psychiatry 2004;67:264-79.

13. Adlina S, Suthahar A, Ramli M, Edariah AB, Soe SA, Mohd Ariff F, et al. Pilot study on depression among secondary school students in Selangor. Med J Malaysia 2007;62(3):218-22.

14. Nolen-Hoeksema S, Girgus JS. The emergence of gender differences in depression during adolescence. Psychol Bull 1994;115:424-43.

15. Undheim AM, Sund AM. School factors and the emergence of depressive symptoms among young Norwegian adolescents. Eur Child Adoles Psychiatry 2005;14:446-53.

16. Angold A, Costello EJ. The epidemiology of depression in children and adolescents. In Goodyer I, editor. The Depressed
Child and Adolescent. Cambridge: Cambridge University Press; 2001. p. 143-78.

17. Melnyk BM, Brown HE, Jones DC. Improving the mental/ psychosocial health of US children and adolescents: outcomes and implementation strategies from the national KySS Summit. J Pediatr Health Care 2003;17:1-24.

18. Mehmet E, Kamil E, Hacer H, Çiðdem D. Prevalence and factors related to depression in high school students. Tur J Psychiatry 2008;19(4):382-9.

19. Birmaher B, Ryan ND, Williamson DE, Brent DA, Kaufman J, Dahl RE, et al. Childhood and adolescent depression: a review of the past 10 years. J Am Acad Child Adoles Psychiatry 1996;35(11):1427-39.

20. Costello EJ, Pine DS, Hammen C, March JS, Plotsky PM, Weissman MM, et al. Development and natural history of mood disorders. Biol Psychiatry 2002;52:529-42.

21. Ramli M, Adlina S, Suthahar A, Edariah AB, Ariff FM, Narimah $\mathrm{AHH}$, et al. Depression among secondary school students: a comparison between urban and rural populations in a Malaysian community. Hg Kg J Psychiatry 2008;18(2):55-61.

22. Reinherz HZ, Paradis AD, Giaconia RM, Stashwick CK, Fitzmaurice G. Childhood and adolescent predictors of major depression in the transition to adulthood. Am J Psychiatry 2003;160(12):2141-7.

23. Shin YM, Cho H, Lim KY, Cho SM. Predictors of self-reported depression in Korean children 9 to 12 years of age. Yonsei Med J 2008;49(1):37-45. 